\title{
A Bit of the 'Other': Media Representations of Young People's Sexuality
}

\author{
MAURICE DEVLIN
}

National University of Ireland, Maynooth

\begin{abstract}
Media representations of young people are an important part of society's ongoing discussion with itself about 'the state of its youth'. This article sets out to explore how the Irish media address the issue of young people and sexuality. Adopting a broadly social constructionist perspective, it presents qualitative case studies of the verbal and visual content of selected feature items in the press and concludes that, at least where sexuality is at issue, young people are envisaged and presented as 'Other', as something puzzling and mysterious. The tabloid and broadsheet press employ similar sets of rhetorical devices to construct this representation and to 'make a spectacle' of the young, often with marked gender differences. There is a consistent 'metaphor of discovery': the 'lifting of a lid' on what young people are 'getting up to', unknown to their parents. There is a pervasive sense of alarm, dismay, of loss and even (ambivalently) of betrayal. It is suggested that in consistently treating young people as 'Other', as predominantly different and difficult, these media representations may themselves be helping to construct and sustain the 'problem' of intergenerational relations.
\end{abstract}

\section{Introduction}

Issues related to sexuality - its nature, its expression and above all its control - are at the very heart of contemporary discourses of adolescence and youth. In fact, it has been suggested that the social significance of adolescence in the modern world can be distilled precisely to the tension between, on the one hand, young people's emerging interest in - and physical potential for - sexual activity, and, on the other, the absence of opportunities for legitimate and socially sanctioned sexual expression (Weeks 1981: 252-3; Springhall 1983: 23). This tension colours all aspects of relations between the generations, and is reflected in media representations of youth: representations principally created and constructed by adults of young people, and therefore inevitably expressive of differential power.

Many such representations are aimed at young people themselves - TV 'soaps' and music programming, 'teen magazines' and so on - and these tend to be dominated by a certain type of highly sexualised content and imagery (regarding teen 
magazines in particular, see McRobbie 1991; Carpenter 1998; Durham 1998). In fact it has been suggested that the media are now the dominant force in the field of Irish sexuality, the one with most influence in shaping young people's behaviour and attitudes:

Media dominance in the field of sexuality has occurred in two ways. Firstly, through the messages produced within soaps, serials, advertisements, the music industry, teenage magazines and so forth which advocate and legitimate the discovery of self and the pursuit of pleasure. Secondly, the media have become the clearing-house for ideas about sexuality. It is through chat shows, talk-radio, and discussion programmes that issues and ideas about sexuality are revealed and discussed. The media have developed a monopoly over setting the agenda for debate and discussion in the public sphere. (Inglis 1998: 111)

According to this reading, media representations of sexuality for the most part reflect a liberal perspective, or 'liberal sexual discourse', which can be contrasted with three other perspectives: the traditional perspective of (in particular) the Roman Catholic Church, the progressive perspective of the state and other agencies (as evidenced by recent initiatives aimed at promoting sexuality education or safe and healthy sexual behaviour), and the radical sexual discourse which links political freedom with sexual freedom and is 'relatively underdeveloped in Ireland' (Inglis 1998: 21). The present writer would accept the validity of these broad distinctions, and specifically the idea that, when addressing (or 'hailing') young people themselves, the media appear to adopt a liberal attitude to sex and sexuality, effectively 'encouraging young people to be sexual' (see Inglis 1998: ch. 4).

However, there is clear evidence that, at least in certain contexts and in relation to certain 'sensitive' themes or topics, the media address young people and adults differently, telling them different 'stories' - even apparently conflicting stories about the same subject or the same event, and perhaps even 'encouraging' them in different directions. (See Devlin 2000, ch. 7, for a detailed case study of differential TV news reporting on the subject of young people and drink.) The present article is concerned with media representations of young people and sexuality which are aimed primarily at adults, and which therefore might be said to be part of (adult) society's ongoing conversation with itself about the state of 'its youth' (this type of use of the proprietorial adjective is examined further below). The concern is not with how closely or accurately these representations reflect young people's actual sexual attitudes and behaviour, nor with the extent to which they would be accepted as valid or accurate by young people themselves (although some limited enquiry by the author in classroom and youth work settings suggests emphatically that they would not). The point of an analysis such as this is that, since adults in society collectively have more power than the young, their discourse - how they think, act and talk among themselves about any given topic - merits separate examination.

As a point of entry to such discourse, and it claims to be no more, the remainder of this article uses case studies of feature items in the press in an attempt to show 
that young people - and specifically young people as sexual beings - are frequently envisaged and presented as 'Other': as something puzzling, troublesome, mysterious, potentially dangerous.' ${ }^{\prime}$ Roger Fowler (1991: 29) has described the press as 'society's major mode of representation of its important and habitual processes'. Fowler, whose influence will be evident in the textual readings which follow, adopts a social constructionist approach to the analysis of language. This is an approach which draws our attention to the 'productive' and even 'prescriptive' capacities of language (both verbal and visual) and representation. Stuart Hall (1997: 24-5) characterises the social constructionist approach as one which recognises language's 'public, social character' and the ways in which meaning is socially produced or constructed rather than simply discovered or unearthed. From this point of view, representation is seen as 'entering into the very constitution of things... and culture is conceptualised as a primary or constitutive process, as important as the material "base" in shaping social subjects and historical events' (1997: 5-6). As seen from this perspective, media representations of social groups, including young people, are not simply 'accounts' or 'reports' of some preexisting reality; they are themselves actively constructive ('constitutive') of the experience of such groups and their relationships with the wider society.

It is important to acknowledge from the outset, of course, that young people do not in fact form a homogeneous group. The concept of 'youth' itself has been variously defined as 'ambiguous' (Berger and Berger 1976: 236), 'complex and slippery' (Valentine et al. 1998: 6), 'fuzzy' (James 1986: 156) and 'liminal and unstable' (Levi and Schmitt 1997: 1, 6). It lacks any clear age-specificity, and unlike both 'child' and 'adult' has no clear meaning in law. ${ }^{2}$ It is also a concept which conceals, or at least might be said to distract attention from, the numerous differences between young people, most notably on the basis of such collective factors as gender, class, 'race' and ethnicity, dis/ability and sexuality. The primary focus on 'young people' in this article is not intended to downplay the significance of these differentiating factors, or the existence of multiple, frequently competing, discourses which impact on the 'young' in different ways (see, for example, Raby 2002). Reference will be made to issues of gender and sexual orientation, in particular, as they arise in the examination of the texts. ${ }^{3}$ However, for the most part, the media sources analysed below themselves focus on 'our children' and 'our young people' as representing 'a problem', and the analysis engages with them on that basis.

\section{'Teen Sex': The Sunday World}

The first item is 'TEEN SEX: THE FACTS', the first installment of a two-week 'special' on youth which appeared in the tabloid Sunday World on $8^{\text {th }}$ and $15^{\text {th }}$ February 1998. It took up, by any standards, an exceptional amount of space in that week's newspaper: the full front page in colour and six inside pages, one of them also in colour (and much the same the second week, which focused on the 'TEENS DRUG DRINK SHOCK'!). 


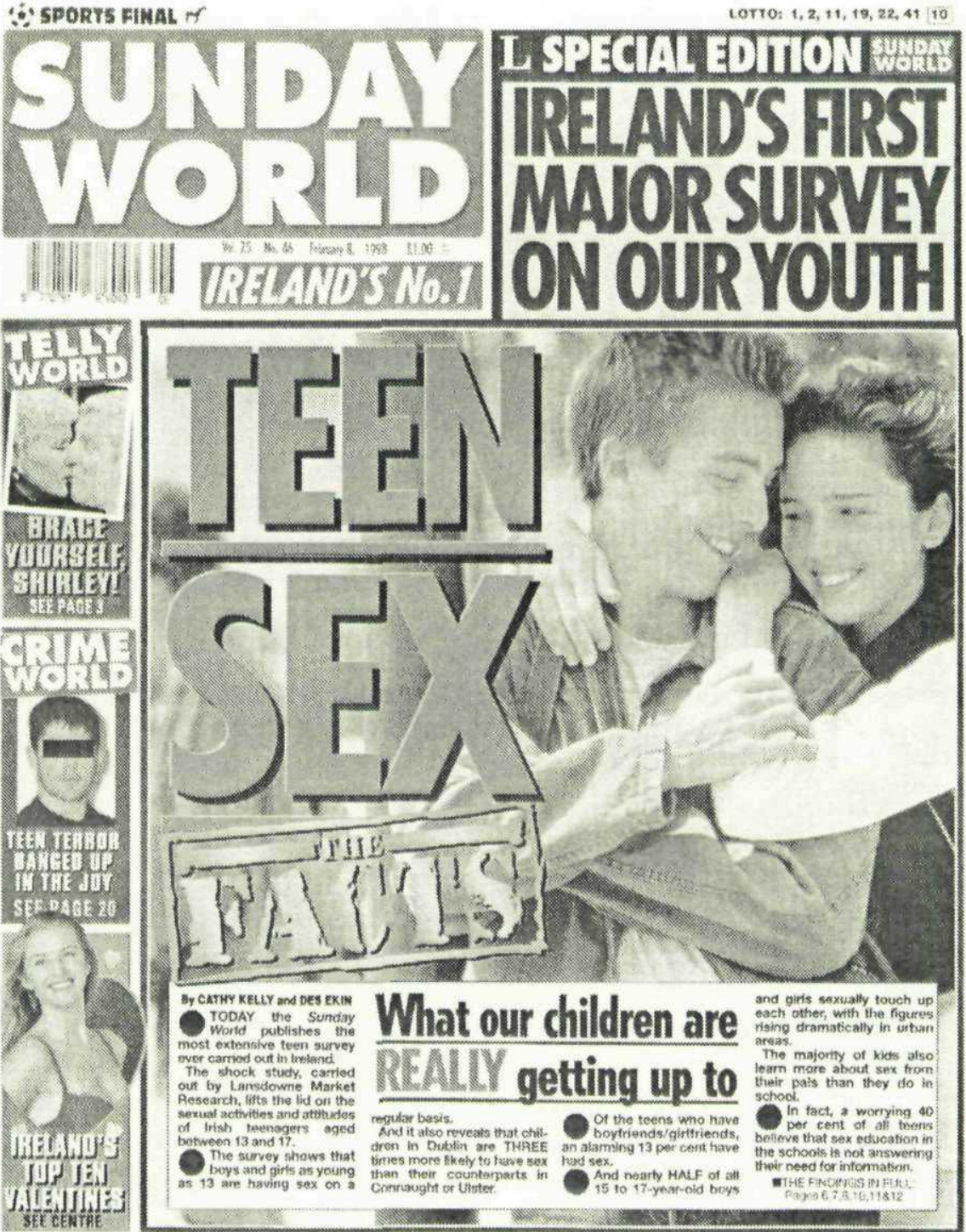

What is immediately striking, to use a term from linguistics, is the nature of its modality. Roger Fowler (1991: 85) defines modality as the 'comment' or 'attitude' which the speaker or writer can be seen to hold, explicitly or implicitly, with regard to whatever is being spoken or written. He suggests that there are (at least) four types: truth, obligation, permission and desirability. Each of these types of modality can operate in different directions (e.g. 'false'/ 'true'). They can also operate to different degrees ( 'absolutely false'/ 'substantially true' and so on). In the case of this Sunday World cover we are left in no doubt as to the editorial view of the status, in terms of 'truth', of the material being presented, making this an 
unusually good example of what Ferguson (1998: 269) calls the "certitude of the tabloid headline'.

The main photograph on the front page is of a smiling young man and woman. Compositionally, both in terms of the graphic design of the page and the relative posture of the participants, he has the 'dominant' position, an arrangement typical of this type of portrayal of young heterosexual couples (see for example Durham 1998: 374-5). Superimposed on the photograph are the words 'TEEN SEX'. They are not only in bold red capitals, they are underlined; and just overlapping the second underline mark at a slightly skewed angle is a box with the words 'THE FACTS' in it. The box and the words have the image of an official stamp mark. Its 'authenticity' is conveyed in two ways: both by the skewed angle, as if it were not part of the normal page layout but had been added afterwards as part of some checking or verification process, in the way an official stamp would, and by the small imperfections in the pattern of the ink on the paper, suggesting the stamp is well worn. The next most prominent words on the page tell us that this is 'Ireland's first major survey on our youth' (which is not in fact the case: among the earliest Irish youth surveys were Market Research Bureau of Ireland 1984; Irish Marketing Surveys 1987). In addition to making this claim - which in terms of modality enhances the status of the survey - it is significant that it uses the term 'our youth', a proprietorial formulation which draws attention to the shared perspectives and concerns of the newspaper and its readership, and which is paralleled in the six inside pages, on each of which the words 'The most in-depth survey ever carried out on our children' appear across the top. The text box at the bottom of the front page also stresses the truthfulness and reliability of the material: 'What our children are REALLY getting up to'; '.. the most extensive teen survey ever carried out in Ireland'; '...shock study...lifts the lid on the sexual activities and attitudes of Irish teenagers...'.

A further significant feature of this front page image of young people, again using a term drawn from linguistics, is the variety of lexicalisation. Fowler (1986: 151) defines lexicalisation as 'simply the existence of a word for a concept.... and of sets of words for families of concepts'. The lexical structure of any text can be thought of as a 'distinctive set of relations and processes' because the type of words, and the very number of words, that relate (in any one language) to a given concept can give us insights into significant features of the culture and society in question. For instance, overlexicalisation, which is 'the availability, or the use, of a profusion of terms for [the same] object or concept', tends to indicate 'an unusual preoccupation with a part of the culture's, or the writer's, experience' (1986: 155), and often also to indicate unequal power relations. A notable case of overlexicalisation in the English language is the proliferation of words, frequently pejorative, for designating women. Overlexicalisation also applies in the case of young people, and is abundantly evident even on this one page of the Sunday World, with its references to 'our youth', 'teen survey', 'Irish teenagers', 'boys and girls', 'our children', 'teens', and 'kids'. Far from being simply a technical linguistic 
consideration, or a matter of stylistic flourish and variety, lexicalisation is 'an integral part of the reproduction of ideology... [and] the basis of discriminatory practice when dealing with so-called "groups" of people as women, young people, "ethnic minorities", and so forth' (Fowler 1991: 84).

Pages 6 and 7 of this edition of the Sunday World form a 'spread', and as on the first page the modality stresses the veracity of the findings, and suggests that the 'lid is being lifted' on something surreptitious, illicit and previously hidden: the things 'teens get up to'. The main banner headline reads 'The truth about Irish teenagers'; the sub-headline is 'The first survey to tell you what REALLY goes on with today's children'; and the caption to the main photograph reads 'THE TRUTH AT LAST". The main article on these pages presents an overview of the survey. It begins:

TEENAGERS... you know what they're like. Oh no you don't - you just THINK you do.

If you re an adult, you probably imagine you know all about the teenagers in your life - your children, your younger brothers and sisters, your nephews and nieces, or your pupils.

You probably think you have a pretty good insight into their opinions, their lifestyle. their aspirations, their knowledge of the facts of life and of safe sex, the likely extent of their sexual experience, and their awareness of the dangers of drugs.

If you're responsible for their welfare, you may think that you've educated them about the risk of pregnancy and sexually transmitted disease, and that you've protected them so well that they' re unlikely to have any contact with drug dealers.

Well, today we have news for you: YOU'RE WRONG.

The basis for this degree of certainty that the reader is 'wrong' is the fact that the survey, carried out by Landsdowne Market Research in accordance with standard quota sampling procedures, involved interviews both with young people (" 400 13-17 year-olds') and with parents ('200 parents of teenagers aged 13-17'), and according to the findings as presented there are indeed many cases of substantial divergence between the responses of the two groups. However, the reliability and validity of these survey results (based on 'confidential self-completion questionnaires') and their status as 'facts' about the actual behaviour of young people are treated as being entirely unproblematic:

Around one in every 10 Irish children of secondary-school age (between 13 and 17) has had experience of sexual intercourse...

You may be surprised to learn... that if your 13 or 14-year old son has a girlfriend. there's a one-in-eight chance he is having sex with her... yet he's unlikely to be aware of how babies are conceived...

Dublin teenagers are THREE TIMES more likely to have had sex than their counterparts in the north west.

Nearly one in ten teenagers have been naked together...(No farmers' teens have done this!). 
One in ten blue collar youths $(10 \%)$, less than one in ten $(6 \%)$ middle income kids have had sex and no farmers' teens have had sex at all.

What is of most interest here, however, rather than the findings themselves (which may or may not correspond to actual sexual behaviour and experience), is the selection of strategies and methods for representing the findings. In addition to the rhetorical and linguistic strategies already mentioned (relating to modality and lexicalisation) another is the liberal use of photographs of young people - singly, and in couples and groups - to add authenticity, the 'human dimension', to the facts and figures. However, a small by-line under one of the photographs reads 'Pics [plural] posed by models', which suggests that all the photographs in this 'survey special on youth' feature models.

A further significant aspect of this feature on young people and sex - the most 'comprehensive' ever of its kind, we are told repeatedly - is the fact that it does not address at all, either in the written text or in any of accompanying photographs, the possibility of young people being anything other than heterosexual. It appears that the questionnaire asked the teenage respondents what they knew about homosexuality (no mention is made of bisexuality), but not about their own sexual orientation. Once again the findings in this regard are presented as unproblematic, including the 'fact' of young women's greater 'knowledge about' homosexuality (although it is not clear what 'knowing about' homosexuality means):

\begin{abstract}
Homosexuality. Girls are much more likely to know about homosexuality than boys. In fact, in the older age groups, girls are twice as likely to know about homosexuality $-46 \%$ of girls compared to $27 \%$ of boys. Again, farming community kids are only half as likely to know about homosexuality. But the overall knowledge on homosexuality was very bad and the 'know very little' categories here were the highest for all this section - three out of ten rural kids knew nothing or very little about homosexuality, while over two out of ten urban kids admitted the same.
\end{abstract}

It might be suggested that it is not surprising that the "overall knowledge on homosexuality was very bad' given the way in which the subject had been addressed (or not addressed) in this survey and in other comparable studies and reports. A study of Irish youth work policy documents by Devlin (1989) found a conspicuous inattention to the existence of young lesbians and gay men and suggested that this is a potent example of what Foucault (1972: 35) calls the "not said': 'The manifest discourse...is really no more than the repressive presence of what it does not say; and this 'not-said' is a hollow that undermines from within all that is said .'

\title{
'Sex Games': The Irish Times
}

We can compare the coverage of young people's sexual behaviour in the Sunday World with a feature article in the 'Weekend' supplement of The Irish Times published on 17th October 1998 (Plate 2). The Irish Times is widely regarded - 
and regards itself - as the 'newspaper of record' in the Republic of Ireland. The article is about sex education and specifically about the Relationships and Sexuality Education (RSE) programme which was then being introduced in Irish schools. It is also a 'news' feature in that it ties in with the publication of a book by sociologist Tom Inglis called Lessons in Irish Sexuality (1998) and a smaller accompanying article presents some of the book's findings. The main text is primarily about the 'struggle between two world views', two conflicting perspectives on sexuality. One is the perspective of 'traditional Catholics' who want to 'protect the family; maintain moral standards; safeguard the innocence of children for as long as possible'. The other is that of 'the liberals... who want to bring an end to the once all-powerful ancien régime of repressive Catholicism'. The article acknowledges however that neither of these groups is 'as homogeneous as is sometimes supposed' and gives a measured account of some of the complexities involved, including the suggestion by Inglis that Irish people are 'ambivalent about sex':

... 'they want the best of both worlds'. Young people have to learn to deal with this ambivalence. Learning to be 'sexually street-wise' means realising that there are two sides to every street: the Catholic side of chastity and modesty, and the liberal side of sexual experience. A parallel ambivalence comes from living in a contraceptive culture', so that parents and teachers do not know whether to teach 'chastity or safe sex'(Inglis 1998: 175).

Such complexity is scarcely captured, however, by the visual representation

accompanying the article. This consists of a large colour photograph of a group of young people lying on the ground, apparently at a rock concert. Eight are fully or partially in shot: four young men, three young women and the eighth unclear. The caption reads: 'Age of innocence: young love at the Slane concert, Co Meath in August'. The ground is littered with crumpled plastic and paper drinking beakers. The arrangement of the human participants again corresponds to the pattern identified above whereby males are portrayed in 'dominant' positions. Two couples are engaging in (hetero-) sexual activity, in both cases the young man lying fully or partially on top of the young woman. In one case - in the foreground of the photograph - the young man has one hand underneath the young woman's t-shirt, and his other hand may be inside the back of her trousers (the image is unclear). A third young man has his arms outstretched and is holding in both his hands the hand/arm of a young woman who appears to be asleep. In fact, several of the young people look as if they might be asleep or on the verge of sleep, including the young woman with a hand under her t-shirt.

I would argue that the intended or 'preferred' reading of the photograph is of debauched and decadent lifestyles. Any image chosen for a newspaper article is chosen on the basis that it will 'strike a chord' with the readership. As Chris Jenks (1995: 15) has put it: 'Semiotics cannot proceed on the basis that signs mean different things to different people; on the contrary it depends on a cultural network that establishes the uniformity of responses to/readings of the sign'. He adds, echoing Jay (1992), that 'this network is our 'scopic regime'. Scopic regimes have elsewhere (Evans and Hall 1999: 6) been defined as 'particular and historically specific combinations of meanings and subjects' and as referring to the 'ways in which both what is seen and how it is seen are culturally constructed' (Rose 2001: 6).

This image in The Irish Times can be interpreted as one example of the contemporary Irish (and of course not just Irish) 'scopic regime' of youth and sexuality. Furthermore, it is a very self-consciously 'scopic' representation: it is an image from above (literally a 'surveillance') of young people who look (or have been asked to look?) as if they do not know they are being looked at. In a very particular sense the newspaper reader is here cast in the role of voyeur, all the more so since some of the young people are engaging in intimate activity. This sense is also heightened by the deliberate blurring of the face of the young woman in the foreground of the picture, adding both to the 'authenticity' of the image and the 'surreptitiousness' of our looking at it, as well of course as being an expression of 'respect' for the young woman's 'privacy' and a commitment to the highest ethical and professional standards, as befits a ‘quality' newspaper.

The impact of the photograph is enhanced by the verbal accompaniment. Captions are crucially important in 'anchoring' the meanings of visual images: they can be the 'most important part of the shot' (Benjamin quoted in Evans and Hall 1999: 7). As Barthes (1999: 37-8) put it, 'all images are polysemous; they imply, underlying their signifiers, a "floating chain" of signifieds, the reader able to choose some and ignore others.' It is the text which 'directs the reader through 
the signifieds of the image...[B]y means of an often subtle dispatching, it remote controls [the reader] towards a meaning chosen in advance'. There are two pieces of text which relate to this photograph. The first has already been mentioned, the small caption beside the upper right-hand corner of the photograph which reads: 'Age of innocence: young love at the Slane concert, Co Meath in August'. This is clearly heavily loaded with irony, intended it appears to communicate the direct opposite of what it says: 'These people are far from innocent and this is lust, not love'.

The second, and much more prominent, verbal 'foil' to the visual image is the headline for the article, in bold red letters (as was the 'TEEN SEX' headline in the Sunday World) located directly beneath the photograph. It reads 'School for Sex'. The juxtaposition of the words 'sex' and school' is eye-catching (the words do not often appear together in this way, and 'sex' is probably not something most people would associate with 'school'). As well as this marketing function, 'selling' the article to the reader, the headline is obviously a direct reference to its content: the provision, in school, of education about sex. But, at least as importantly, it also seems designed to act as a cue for the reader/viewer's interpretation of the photograph, directing him or her to see it in a certain way. It seems to suggest - particularly when read alongside the other caption - that 'this is what young people are learning about in their leisure-time': 'this is what they get up to'. In rhetorical terms, and adding to the irony already noted, both the internal construction of the headline, and the text/image relation of the headline and the photograph, contain strong elements of paradox ('sex, and this type of behaviour in general, is a far cry from school').

All told, therefore, I would suggest that this very prominent visual representation of the young, and the accompanying captions - unlike, it is important to reiterate, the main body of the journalistic text - is not very dissimilar from that which appears in the Sunday World's survey feature, with the important difference that the Sunday World specifically indicates, albeit in a tiny reference, that the images are of models (and therefore that it is not 'invading' anyone's 'privacy'). In a manner typical of much media representation of the young. The Irish Times here makes a spectacle of (this group of) young people (see Debord 1977; Hebdige 1983; Acland 1995). The reader might imagine the parent of one of them, on recognising their son or (especially perhaps, given the 'double standard' relating to sexuality) their daughter in the photograph, bewailing the fact that their child had 'made a show' of her/himself, whereas what has happened is that a show has been made of them. This photograph is a particularly clear reminder of Sontag's suggestion (1999: 93) that the camera helps to define reality in 'the two ways essential to the workings of an industrial society': as a source of spectacle and as an object of surveillance.

Two other examples of representations of young people in The Irish Times will illustrate the similarities, in certain important respects, with tabloid newspaper rhetoric. One is a feature article in the 'Education \& Living' supplement of $23^{\text {rd }}$ March 1999. The cover of the supplement features a set of visual images 
representing various aspects of young people's lives: school, romance, alcohol, relationships with parents. Under these images, in bold black capitals (capitals, significantly, are not used in headlines in the body of The Irish Times, whereas of course they are common in tabloid headlines) is the word 'TEENAGERS', and beneath it the question: 'Is there a problem?' The question is a rhetorical one. When we turn the page the banner headline to the article (again in bold capitals) gives the unequivocal answer: 'TOO FAR, TOO YOUNG' (yes reader, there is a problem). This is despite the fact that the body of the article contains evidence which is 'mixed' (and, as it says itself, 'sketchy') and a variety of views on the matter of whether teenagers' sexual behaviour is a problem. One school principal is quoted as saying: 'It's a gross exaggeration to say that teenagers are out [of] control or that they are not amenable to advice... The vast majority of young people are very amenable to the values that their parents exercise.' The article notes the 'dearth of data on sexual activity' and draws attention to one survey conducted in Cork (with the title What on Earth Are They Doing?). The three photographs accompanying the article are all taken from popular recent American films and the caption says 'How Hollywood treats teens'; but the body of the text does not make any reference to the relationship between these Hollywood images and the sexual lives of Irish of young people. Overall, therefore, the piece amounts to little more than a bold and colourful assertion that young people's sexual behaviour is a problem, with scarcely any substantiation or analysis.

The final example from The Irish Times is a feature article published on $17^{\text {th }}$ July

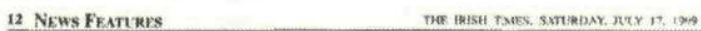

They are 14 or 15 years old and they get drunk on cider before pairing off for experimental 'meetings' in the woods

\section{Our children and their sex games}

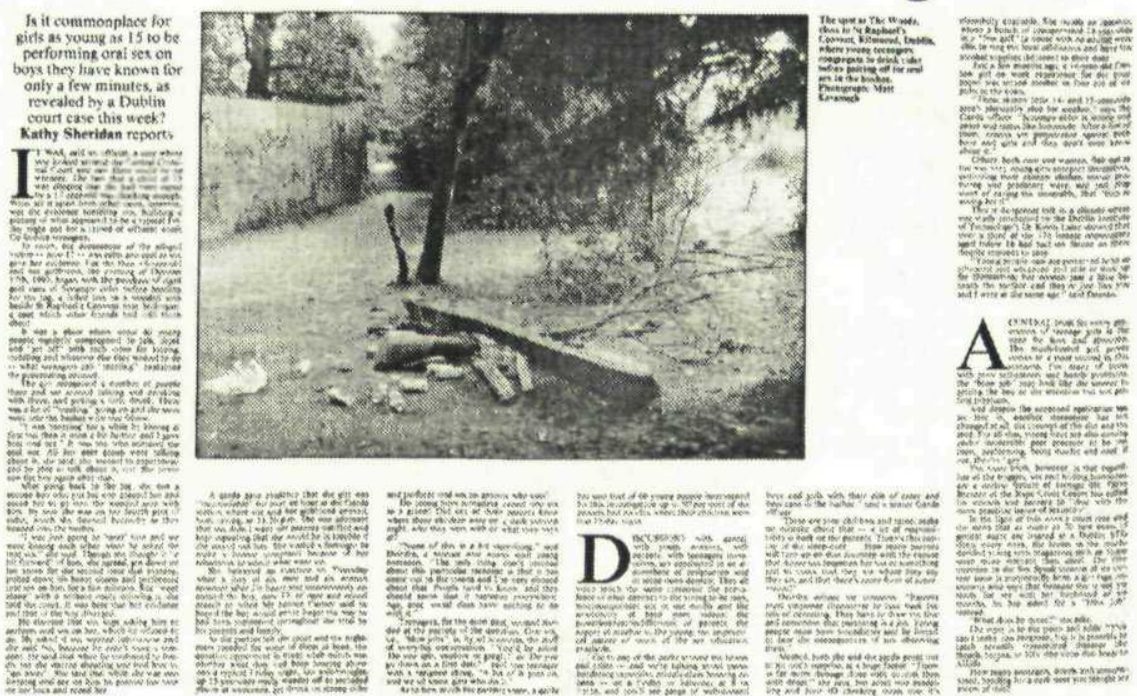


1999 entitled 'Our children and their sex games'. It appeared a few days after a court case in which a young man was acquitted of rape and sexual assault of a young woman (they had been 17 and 15 respectively at the time of the alleged incident).

As in the Sunday. World survey, the 'our' in the headline adds to the sense of shared concerns and worries (and even of ownership) between the writer, the newspaper and its readers. The word 'games' is also worthy of note, juxtaposed with 'sex' much as 'school' was in the 'School for Sex' feature, but with the added (alarming) resonance here of being associated with the word 'children'. The 'message' of this article is communicated with a striking degree of insistence. In addition to the main headline there is an introductory paragraph consisting of a single question: 'Is it commonplace for girls as young as 15 to be performing oral sex on boys they have known for only a few minutes, as revealed by a Dublin court case this week?'. It might be noted that, in this article about the sexuality of 'our children', it is the behaviour of young females which is highlighted as deviant by the linguistic formulation of the introduction. There is an additional sentence running along the top of the page, above the main headline, with the words (underlined) 'They are 14 or 15 years old and they get drunk on cider before pairing off for experimental 'meetings' in the woods'. Finally there is a caption in bold letters accompanying the very prominent black and white photograph: 'The spot at The Woods, close to St Raphael's Convent, Kilmacud, Dublin, where teenagers congregate to drink cider before pairing off for oral sex in the bushes'.

Rhetorical devices similar to those seen above in the Sunday World's youth survey feature prominently both in the main narrative and in the reported comments from professionals (rhetorical questions, speech acts, emphatic terminology and repetition, evocative words and phrases):

As the parties left the court and the nightmare receded for some of them at least, the question uppermost in many adult minds was whether what they had been hearing about was a typical Friday night. Do well-brought-up 15-year-olds really wander off to secluded places at weekends, get drunk on strong cider and perform oral sex on anyone who asks?

Do young boys nowadays expect oral sex as a given?

Did any of their parents know where these children were on a dark autumn night. who they were with or what they were at?.....

"Go to any of the parks around the towns and cities - and we"re talking about parks bordering expensive middle-class housing estates - on a Friday or Saturday at 8 or 9 p.m. and you'll see gangs of well-dressed boys and girls with their pile of cider and beer cans in the bushes," said a senior Garda officer.

"These are your children and mine, make no mistake about that - a lot of the responsibility is back on the parents."

There is further evidence of the 'double standard' regarding sexuality and the suggestion that the reputation of young women (particularly perhaps 'well broughtup ones') is at stake in a way that does not apply to young men (on 'reputation', see 
for example Kehily 1999: 75-7).

Teenagers, for the most part, seemed startled at the naivety of the question [as to how they behave sexually]. Oral sex, i.e., "blow jobs", is by all accounts, the stuff of everyday conversation. "You'll be asked 'Do you spit, swallow or gargle?' or 'Do you go down on a first date?"” said one teenager with a resigned shrug. "A lot of it goes on, and we all know girls who do it."

The item closes in familiar rhetorical terms. Having quoted from an advice column in a 'teen magazine' to the effect that oral sex 'can't make you pregnant but it is possible to catch sexually transmitted diseases' it asks: 'How many teenagers, drunk and unsupervised, heading for a park near you tonight are aware of this?' In addition to the interrogative mood, this is given added rhetorical impact by its play on a phrasing commonly used in advertising ('coming to a cinema near you...'), which is of course the most rhetorical of professions (see for example Barnard 1995; Burgin 1999). If the reader wishes to call such a park to mind, he or she can look for inspiration to the photograph accompanying the article, a highly unusual image for a newspaper to publish since there is no human presence and nothing is 'happening' in it. It is simply a photograph of a place, but a rather unattractive place and - were it not for the court case - hardly one that would be likely to find itself the subject of a newspaper photograph. It is 'the spot at The Woods' and in the centre foreground is 'the log' (a length of wood but not strictly a ' $\log$ ' at all) where young people congregate. Scattered around the log are a bottle and a number of empty cider or beer cans, some crushed, and a discarded paper wrapping. There is no way of knowing whether this is the scene 'as found' or if anything was moved, changed or added (e.g. the log or other pieces of wood; the bottle, cans or paper). To the left is a wall of corrugated iron sheeting substantially covered with graffiti.

Obviously, this 'spot in the woods' could have been photographed in a variety of ways and from a variety of angles. The shot as presented here, despite the 'drabness' of the scene on first appearance, has the composition of a 'good photograph', with a striking play of light and dark and other types of contrast (an important part of the photographer's 'stock-in-trade' - see Burgin 1999: 45). There is also a very strong sense of perspective. As seen from this angle, the log lies close to a junction where the pathway bifurcates, and there are therefore two separate laneways going off 'into the distance', away from the viewer. Such a use of perspective is typical of many centuries of tradition in European visual culture, and John Berger has suggested (1972: 138) that it is one of several features held in common by media as diverse as 'great' oil paintings of the past and contemporary shop front displays, in both cases serving to 'offer mystery' (for more general comments on compositional analysis see Rose 2001, ch. 2). Also 'mysterious' in this photograph is the clump of trees and bushes in the centre, between the two pathways (and dark and murky in contrast to the light falling on them), and only a few yards from the log. The reader/viewer is presumably to suppose that these must be the bushes where the 'young teenagers' have their 'experimental meetings' 
and 'oral sex' on 'dark autumn nights'.

This can be seen as an example of the camera acting as an 'inscription device' (Latour 1987), 'convincing others at a distance'. In a discussion of the work of Latour and others on the historical development of scientific and technological 'authority', Andrew Barry (1995: 49) remarks:

Since the nineteenth century...one way of obtaining reliable knowledge of distant events has been to depend on the discipline of the observer. In this way, the visualisation of the far-away and the foreign has become increasingly technological not in the sense that it is dependent upon hardware. but in the sense that it has come to rely upon the possession of technical competence and the construction of relatively standardised forms of visual and literary representation.

Photographic skill is one such 'technical competence', and this photograph in The Irish Times one example of a 'relatively standardised visual representation'. Along with the text of the article, it is informing (or 'convincing') the reader of the existence and the nature of what Barry calls the 'far-away and the foreign', not obviously in a literal sense (after all, we are told several times that the behaviour in question 'happens everywhere' in this country, regardless of 'age, area, social class'); but in the sense that the young people whose activities are so graphically described in the text, and whose presence might be said to 'haunt' the visual image, are represented as 'Other', as a 'mystery' (can it be so?; is this really happening?; among our very own children?).

This photograph, with its lack of human participants (explicitly, at any rate) or of any direct action, and with the suggestiveness of the strewn cider or beer cans, as well as the suggestiveness of the text (how many teenagers...park near you tonight... etc) is also a very good illustration of a further point made by John Berger (as quoted in McQuire 1998: 59): 'An instant photographed can only acquire meaning insofar as the viewer can read into it a duration extending beyond itself. When we find a photograph meaningful we are lending it a past and a future'. The 'past and the future' of this photograph have, of course, been provided for us by the verbal context. If the meaning of a image is indelibly shaped by what comes before and after' (McQuire 1998: 61) then the meaning of this image appears to be that 'our children' - our 'mysterious' and 'troublesome' children - are engaging in 'sex games' in the bushes; and that, whether you know it or not, many of them will be 'heading for a park near you tonight', a park like this one perhaps, to do just that. Despite clear differences of style and wording this representation of young people, in terms of the intended impact on the reader (insofar as this can be judged) and the degree of 'moral panic' conveyed about the behaviour of the young, appears not dissimilar from 'TEEN SEX: THE FACTS' as featured in the Sunday World.

\section{'Lost Tribe': The Sunday Independent}

The article in The Irish Times was not the only one prompted by this particular court case. The following day $\left(18^{\text {th }}\right.$ July 1999) an 'opinion piece' by psychologist 
Patricia Redlich in the Sunday Independent (a popular broadsheet - the biggestselling Sunday newspaper in Ireland) struck a very similar note, although it was not accompanied by any visual illustration, and for that reason usefully highlights the impact of the photograph in The Irish Times. Its title shares with the headlines in the Sunday World and The Irish Times an evocation of 'community', of 'us'. However, much more explicitly than either of the two other newspapers it identifies young people as them, as Other. In doing so it uses terminology richly suggestive of colonialism and a traditional paternalist anthropology (for comments on the parallels between adolescence and 'other subjugated peoples' see Lesko 2001; Raby 2002). It also calls to mind Barry's remark (quoted above) about the 'far away and the foreign':

'We have failed our tribe of lost children.'

The opening paragraphs are very similar to the article in The Irish Times in that they give a detailed account of the events on the night of the alleged incident which prompted the court case. Both give details of the location of 'the log', of the amount of drink bought by the two young women, of the use by this group of young people of the term 'meeting' to refer to sexual activity, and of the young woman's encounter with one young man and the fact that it was she who 'initiated oral sex' with him. Both also tell of how, having taken some more cider she 'headed into the bushes' (I.T.)/ 'retreated into the bushes' (S.I.) with a second young man and 'got down on her knees for a second time that evening' (I.T.)/ 'was willingly down on her knees...' (S.I.). The similarity in the graphic description of the young woman's physical posture and behaviour is striking, suggesting perhaps that this terminology featured prominently in the court case itself (and adding, it could be argued, to the sense that it is her behaviour which is disreputable). Having given details of the outcome of the case the Sunday Independent article goes on to reflect about it. As in The Irish Times article, the prevalence of this type of behaviour throughout the country is asserted, and one of the most famous phrases in twentieth century Irish history is invoked ironically to convey just how bad things have become:

This is no isolated incident...It's far more than merely a cautionary tale. The picture painted during this trial of "meeting" in places like "the log" is one that applies all round the country, in city, town and village. De Valera's notion of dancing at the crossroads has taken a distinctly ugly turn. And every community knows it.

The reality is that as a society we have spectacularly failed our youth.

The problem is not just alcohol abuse, or the fact that 'drugs are so freely available to young people' even outside the cities:

We have collectively suffered a crisis of authority - not just parents, but the whole adult world, community, institutions, the state. And in that crisis, we have abandoned youth.

After an anecdote about the writer's own family the point is made that fifteen years ago 'society had already washed its hand of our young'; but that there is 'an 
even sorrier tale'. A series of statements is then made, each of which implicitly suggests the nature of the 'world that was', of what has been 'lost' (the author's interpretation of the latter is given in italics in each case):

Sex and love no longer go hand in hand ['sex and love went hand in hand in the old days $s^{*}$. Sex no longer has even necessarily anything to do with pleasure or happiness ['in the past sex necessarily had to do with pleasure or happiness']. For very many of our children, the notion of waiting until you find someone special is entirely old hat ['very few' of our children thought like this in the old days']. Sex itself is not seen as anything special ['sex has hitherto been seen as something special'].

The closing paragraphs link these modern attitudes to sex (and the fact that, according to the author's experience of the 'teens columns', 'girls must now be courtesans, young men experienced lovers') with a wider malaise. The ultimate result, says the author, will be people fighting for 'better pay on the buoyant tide of the Celtic Tiger' but not for 'health, peace of mind, leisure, family time, personal dignity and self-respect'. Again there is an 'unproblematic' assumption that people have 'fought for' these things in the past: 'They won't defend themselves properly in the workplace ['as they have in the past']. Or in their personal relationships ['as they have in the past']'. The article concludes with a restatement of the 'crisis of authority' and with a by now familiar formula of a series of rhetorical questions:

But the real problem is that in our abdication from the role of proper authority, we adults are failing to give our youth a real moral framework for sex and love, dignity, personal worth and human integrity.

Without standards, how can they judge themselves and others properly? How can they know what to aspire to? How can they know how to value themselves? How can they ever be anything but lost?

The notion of young people as 'lost' is not a new one, and variations on it have appeared in the newspapers many times over the years. A feature article about Irish young people in the British Sunday Times in 1986 was entitled 'Ireland's Lost Generation'. The use of the word 'generation' in this context is itself significant, implying as it does that the entire future of the society is at stake. The Sunday Independent article does not use the word 'generation' but its point is the same: the crisis has affected 'the whole adult world, community, institutions, the state'. It says that adults have 'failed their lost children' 'abandoned their youth', 'abdicated proper authority'. However, what is ultimately presented as having been lost (the 'even sorrier tale', in the author's own words) is a particular kind of society, based on a particular set of values and a particular association between 'love' and 'sex'.

\section{Conclusion}

The media representations of young people's sexuality examined above have been characterised predominantly by a sense of alarm, dismay and even of loss; a sense 
that something mysterious, possibly sinister, is happening among 'our youth' and that consequently the very nature of 'us', of 'our society', is under threat. There are gender differences within the representations, and ample evidence of the 'double standard' on sexual behaviour, but the sense of alarm about 'young people' in general is pervasive. It is equally present in the broadsheet and tabloid newpaper items, which are found to use very similar rhetorical devices, verbal and visual, in their construction and representation of young people as a 'problem'. This is not to say there are no differences between tabloid and broadsheet newspapers. It has long been recognised that different newspapers, and types of newspaper, have different 'modes of address' or 'public idioms' (Hall et al. 1978: 61), and this has been borne out in other recent Irish media studies (e.g. Pollak 1999). The author (Devlin 2000) has also found significant differences, in general, between the tabloids and the broadsheets in relation to such matters as grammar, vocabulary, length and style of headline, and use of 'visuals'. However, in the analysis documented here, despite obvious differences of grammar, style and tone, what is most striking is the degree of rhetorical correspondence between the newspapers, suggesting that they operate out of a common 'discursive reserve' (Ferguson 1998) of ideas and assumptions about the nature of youth and the nature of sexuality. This is in keeping with Ferguson's conclusion, in the context of a review of broadsheet and tabloid representations of 'race' (1998: 141), that a 'veneer of sophistication' can enable the 'quality press' to construct and sustain discourses similar to, or compatible with, those of the tabloids. The degree of correspondence between the newspapers also gives added weight to the idea - suggested at the outset of this article - that such media representations are good indicators of broader societal discourse regarding these matters.

The prevalent sense of alarm and loss in the newspaper items seems to be accompanied by an ambivalent suggestion of betrayal: both betrayal of young people ('we have failed them'); and, less tangibly, betrayal by them ('how could they do this to us?'). This is broadly in keeping with Chris Jenks's analysis (1996) of the ways in which models or visions of childhood have been changing as part of the transition from modernity to post-modernity. He distinguishes between childhood as 'futurity' - an embodiment of hope and optimism, in which much is invested for the future ('our primary love objects, our human capital and our future') and childhood as 'nostalgia', in which children are seen not so much as 'promise', as 'primary and unequivocal source of love', but also as:

... partners in the most fundamental, unnegotiated form of relationship. The trust that was previously anticipated from marriage, partnership, friendship, class solidarity and so on is now invested more generally in the child..... we cling to them for 'nostalgic' groundings because [profound] change is both intolerable and disorienting for us. They are lover, spouse, friend, workmate and, at a different level, symbolic representations of society itself (Jenks 1996:19-20).

It is in the light of this, according to Richard Collier (1998: 95), that 'the betrayal 
of the child is so keenly felt':

[T]he relationship between adults and children has itself become as contested a terrain as the breach of the social itself. What appear as contestations around childhood are thus reformed as questions about the (re)constitution of social ( $\mathrm{sic}$ ) within postmodernity: what appear as questions about childhood and children emerge as being, in fact, questions about adults and the adult world.

However, while some aspects of these media representations can be interpreted in the light of the emergent tensions and challenges of postmodernity, others have a Jonger pedigree. A recurrent suggestion in the news stories analysed above is that a 'lid is being lifted' (as if 'we are only now finding out, and bringing to the attention of you the reader, just how bad things are among our youth'). Bessant (1995) suggests that this 'metaphor of discovery' is a common one in press representations of young people. Geoffrey Pearson (1983) has shown that each succeeding generation has been 'discovering' the alarming nature of youth for at least two hundred years, most frequently through the mass media; while Levi and Schmitt (1997) would suggest an even longer history of discoveries. A further element of continuity (and a point touched on already) has been a striking ambivalence in representations of the young - and ambivalence is a recurring feature of what Stuart Hall (1997) calls 'the spectacle of the other'. This can be seen in the texts, verbal and visual, analysed above. Even when the photographs, for instance, are meant to be telling a 'bad news' story, something which is expected to give cause for alarm or concern, the images themselves are often 'pleasing to the eye'. Even if the content in itself is not something the reader/ viewer might feel positively about (a ' log' in a piece of waste ground; a scene of drunken or 'debauched' behaviour), the photograph may be technically constructed, with great skill, to invite us to dwell on it, to take pleasure in looking.

Such constructing, and such looking, can in themselves be ideological (i.e. can express and sustain social interests and relationships, such as relationships between classes, or men and women, or age-groups). As Jessica Evans has put it (1999: 14): 'It is precisely in the formal devices of photographic construction that the workings of ideology reside'. Media representations of young people and sexuality are cases of 'social spectacle', in Debord's sense: 'The spectacle is not a collection of images, but a social relation among people, mediated by images' (1999: 95, emphasis added). In this case the media representations can be seen as not only expressive of, but actively constructive ('constitutive') of, the social relations between adults and young people. They do not simply reflect, but actively help to sustain, the relative lack of power of young people, and the social 'distance' between young people and adults. In treating the young as Other, as predominantly different and difficult, they may themselves, ironically, be a prominent part of the 'problem' of inter- 
generational relations: relations prone to tension in any society, but particularly under strain in a context of rapid and accelerating social and cultural change.

\section{Acknowledgements}

The author is grateful for the constructive comments of the other contributors to this volume at a peer review seminar, and of the two anonymous referees. He would also like to thank Aisling Hurley for a number of useful references. The Sunday World and The Irish Times kindly provided permission for the reproduction of materials.

\section{Notes}

1. The analysis presented here is part of a much broader study, qualitative and quantitative, of representations of young people in the print and broadcast media (Devlin 2000). This involved monitoring the Irish-published national newspapers for an extended period in 1998 and 1999. Of the press items collected, this article concentrates on those with the most specific and explicit focus on young people and sexuality.

2. The Youth Services Bill 1990, a Private Members Bill introduced (unsuccessfully) in the Oireachtas by Jimmy Deenihan TD, included the following formulation (probably too imprecise to have any value in law): " "youth" means the transitional period between the dependence of childhood and adulthood and "young person" shall be construed accordingly'. More recently, "young person" has been defined in different ways in two pieces of legislation: as a 16- or 17-year-old in the Protection of Young Persons (Employment) Act 1996, and as a person under 25 in the Youth Work Act 2001.

3. The study referred to at note 1 above (Devlin 2000) found consistent gender differences in media representations of young people across a wide range of thematic areas (including sexuality, but also drugs and drink, crime, sport etc.).

\section{References}

Acland, C. 1995 Youth, Murder; Spectacle: The Cultural Politics of "Youth in Crisis". Boulder: Westview Press.

Barnard, M. 1995 'Advertising: the Rhetorical Imperative', pp. 26-4in C. Jenks (ed.) Visual Culture. London: Routledge.

Barry, A. 1995 'Reporting and Visualising', pp. 43-57 in C. Jenks (ed.) Visual Culture. London: Routledge.

Barthes, R. 1999 'Rhetoric of the Image', pp. 33-40 in J. Evans and S. Hall (eds) Visual Culture: The Reader: London: Sage/Open University.

Berger, J. 1972 Ways of Seeing. London: BBC/Penguin.

Berger, P. and B. Berger 1976 Sociology: A Biographical Approach. Harmondsworth: Penguin.

Bessant, J. 1995 'The discovery of an Australian 'juvenile underclass', Australia/New Zealand Journal of Sociology, 31(1): 32-48.

Burgin, V. 1999 'Art, Common Sense and Photography', pp. 41-50 in J. Evans and S. Hall (eds) Visual Culture: The Reader. London: Sage/Open University.

Carpenter, L. 1998 'From Girls into Women: Scripts for Sexuality and Romance in Seventeen Magazine, 1974-1994', Journal of Sex Research, 35 (2): 158-69.

Collier, R. 1998 Masculinities, Crime and Criminology. London: Sage. 
Debord. G. 1999 'Separation Perfected' (from Society of the Spectacle), pp. 95-8 in J. Evans and S. Hall (eds) Visual Culture: The Reader. London: Sage/Open University.

Devlin. M. 1989 Official Youth Work Discourse: Aims, Orientations and Ideology in Irish Youth Work Policy, unpublished M.Soc.Sc. thesis. University College. Dublin.

Devlin. M. 2000 Representations of Youth in Ireland, unpublished Ph.D. thesis, National University of Ireland, Maynooth.

Durham, M. 1998 'Dilemmas of Desire: Representations of Adolescent Sexuality in Two Teen Magazines'. Youth and Society, 29 (3): 369-90.

Evans, J. 1999 'Introduction', pp. 11-20 in J. Evans and S. Hall (eds) Visual Culture: The Reader: London: Sage/Open University.

Evans, J. and S. Hall (eds) 1999 Visual Culture: The Reader. London: Sage/Open University. Ferguson. R. 1998 Representing Race: Ideology, Identity and the Media. London: Arnold. Foucault. M. 1972 The Archaeology of Knowledge. London: Tavistock.

Fowler. R. 1986 Linguistic Criticism. Oxford: Oxford University Press.

Fowler. R. 1991 Language in the New's: Discourse and Ideology in the Press. London: Routledge.

Hall, S. (ed.) 1997 Representation: Cultural Representations and Signifying Practices. London: Sage/Open University Press.

Hall. S.. C. Crichter. T. Jefferson, J. Clarke and B. Roberts 1978 Policing the Crisis: 'Mugging', the State and Law and Order. London: Macmillan.

Hebdige, D. 1983 Hiding in the Light: On Images and Things. London: Routledge.

Inglis. T. 1998 Lessons in Irish Sexuality. Dublin: UCD Press.

Irish Marketing Surveys 1987 Young Ireland (commissioned by Irish Youth Foundation). Dublin.

James, A. 1986 'Learning to belong: the boundaries of adolescence'. pp. 155-70 in

A. Cohen (ed.) Symbolising Boundaries: Identity and Diversity in British Cultures. Manchester: Manchester University Press

Jay, M. 1992 'Scopic Regimes of Modernity', pp. 178-95 in S. Lash and J. Friedman (eds) Modernity and Identity: Oxford: Blackwell.

Jenks, C. (ed.) 1995 Visual Culture. London: Routledge.

Jenks, C. 1996 Childhood. London: Routledge.

Kehily, M.J. 1999 'More Sugar?: Teenage Magazines, Gender Displays and Sexual

Learning'. European Journal of Cultural Studies, 2 (1): 65-89.

Latour, B. 1987 Science in Action. Milton Keynes: Open University Press.

Lesko, N. 2001 Act Your Age!: A Cultural Construction of Adolescence. London: Routledge.

Levi. G. and Schmitt. J.1997 A History of Young People in the West; Volume One: Ancient and Medieval Rites of Passage. Cambridge [Mass.]: Harvard University Press.

McQuire. S. 1998 Visions of Modernity: London: Sage.

McRobbie. A. 1991 Feminism and Youth Culture: From 'Jackie' to 'Just Seventeen'. London: Macmillan.

Market Research Bureau of Ireland 1984 Attitudes and Behaviour of the Youth of Ireland (commissioned by the National Youth Policy Committee). Dublin.

Pearson. G. 1983 Hooligan: A History of Respectable Fears. London: Macmillan.

Pollak. A. 1999 'An Invitation to Racism?: Irish daily newspaper coverage of the refugee issue', pp. 33-46 in D. Kiberd (ed.) Media in Ireland: The Search for Ethical Journalism. Dublin: Open Air Press.

Raby, R. 2002 'A Tangle of Discourses: Girls Negotiating Adolescence'. Journal of Youth Studies. 5 (4):425-48. 
Rose, G. 2001 Visual Methodologies: An Introduction to the Interpretation of Visual Materials. London: Sage.

Sontag. S. 1999 'The image-world' (from On Photography), pp. 80-94 in J Evans and S. Hall (eds) Visual Culture: The Reader. London: Sage.

Springhall, J. 1983 'The Origins of Adolescence', Youth and Policy, 2 (3): 20-35.

Valentine, G., T. Skelton and D. Chambers 1998 'Cool Places: an introduction to youth and youth cultures', pp. 1-32 in T. Skelton and G. Valentine (eds) Cool Places: Geographies of Youth Cultures. London: Routledge.

Weeks, J. 1981 Sex, Politics and Society: The Regulation of Sexuality since 1800. London: Longman. 
Copyright of Irish Journal of Sociology is the property of Irish Journal of Sociology and its content may not be copied or emailed to multiple sites or posted to a listserv without the copyright holder's express written permission. However, users may print, download, or email articles for individual use. 